\title{
Design of Triple Band Slot-Patch Antenna with Improved Gain Using Triple Band Artificial Magnetic Conductor
}

\author{
Anumoy GHOSH ${ }^{1}$, Tapan MANDAL ${ }^{2}$, Santanu DAS ${ }^{3}$ \\ ${ }^{1}$ Dept. of Electronics \& Communication Engineering, National Institute of Technology, Mizoram, Aizawl, India \\ ${ }^{2}$ Dept. of Information Technology, Govt. College of Engineering and Textile Technology, Serampore, India \\ ${ }^{3}$ Dept. of Electronics \& Telecommun. Engineering, Indian Inst. of Engineering Science and Technology, Shibpur, India
}

anumoy.science@gmail.com, tapanmandal@rediffmail.com, santanumdas@yahoo.com

Manuscript received January 29, 2016

\begin{abstract}
A C P W$-fed triple band slot-patch antenna is designed to resonate at $3.60 \mathrm{GHz}, 5.86 \mathrm{GHz}$ and $8.53 \mathrm{GHz}$. The structure makes use of two types of radiators. A slot structure is made which behaves like a half wave dipole at $3.60 \mathrm{GHz}$. The other two resonating frequencies are generated by two metallic structures inserted within the slot. All the three resonant frequencies are independent of each other. Moreover, to achieve better gain, a triple band artificial magnetic conductor (AMC) is designed and placed at a certain distance below the antenna structure. The AMC shows zero reflection phase at all the three resonating frequencies of the antenna. A detailed analysis of the AMC is presented. Significant improvement in gain is obtained at all the three resonating frequencies. Radiation patterns of the antenna are stable with considerably low cross polarization in both $E$ and $H$ planes in all the three frequencies. A prototype of the triple band antenna with AMC is fabricated and the measured results are in good agreement with the simulated results.
\end{abstract}

\section{Keywords}

Triple band, slot-patch, gain, artificial magnetic conductor (AMC)

\section{Introduction}

Multiband antennas have been the subject of research for quite a long time. Previous works include stacked patch radiators [1], [2], slots on patch radiator [3], [4], interconnected patch or slot radiators and defected ground planes [5-7]. These structures either increase the profile of the antenna or consume a significant area of the antenna substrate or cross polar radiation increases. Moreover, these structures do not provide significant gain. Partially reflecting surface above the antenna [8], artificial magnetic conductors [9], [10] and metamaterials [11], [12] have been used for gain enhancement. But none of them have been used for improvement of gain of multiband antennas.
At a certain frequency, AMC has the property of reflecting the incident wave without any phase reversal behaving as a perfect magnetic conductor (PMC) [13]. Various AMC structures [14-18] have been developed to behave as PMC at multiple frequencies. Previous literature show that gain enhancement using AMC is limited to single and dual band antennas only. Though in [18], a triple band $\mathrm{AMC}$ has been designed to provide three separate resonant bands where it gives high gain, it does not increase the gain of any existing resonant band.

This work proposes a new type of antenna which uses both slot and patch as radiators. The lowest frequency is generated by a CPW fed slot antenna. The other two frequencies are obtained by placing two different metallic radiators symmetric to the feedline. The metallic radiators are so designed that they occupy the space of the slot antenna. Hence, the surface area acquired by the antenna does not increase. Triple band AMC is designed which behaves like PMC at the corresponding frequencies of the triple band antenna. The AMC unit cell has three resonator structures to excite PMC characteristic at triple frequencies. This AMC is used at a minimum distance below the antenna substrate where impedance matching is satisfactory at the triple frequencies. The AMC increases the gain of the antenna at all the three frequencies significantly.

\section{Design Considerations}

\subsection{Triple Band Antenna Geometry}

Figure 1 shows the progressive development of the CPW fed triple band antenna. The antenna is designed on FR4 substrate with relative permittivity $\varepsilon_{\mathrm{r}}=4.4$ and loss $\operatorname{tangent} \tan \delta=0.02$. The dimensions of the substrate are $60 \mathrm{~mm} \times 60 \mathrm{~mm} \times 1.6 \mathrm{~mm}$. The feedline has length $30.5 \mathrm{~mm}$ and width $W=3 \mathrm{~mm}$. Antenna 1 consists of a slot radiator with dimensions $\mathrm{S} 1=22 \mathrm{~mm}, \mathrm{~S} 2=3 \mathrm{~mm}$, $\mathrm{S} 3=9 \mathrm{~mm}$. It behaves as a half wave dipole antenna. Antenna 2 consists of two symmetrically placed split ring 


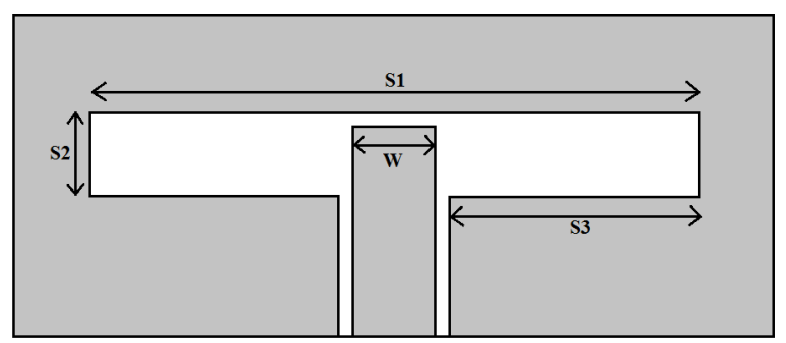

(a)

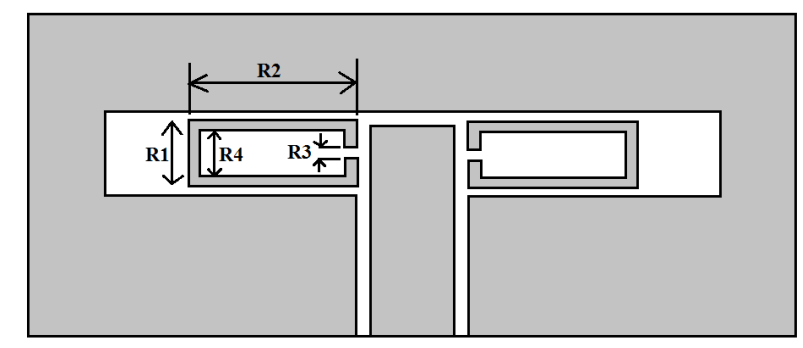

(b)

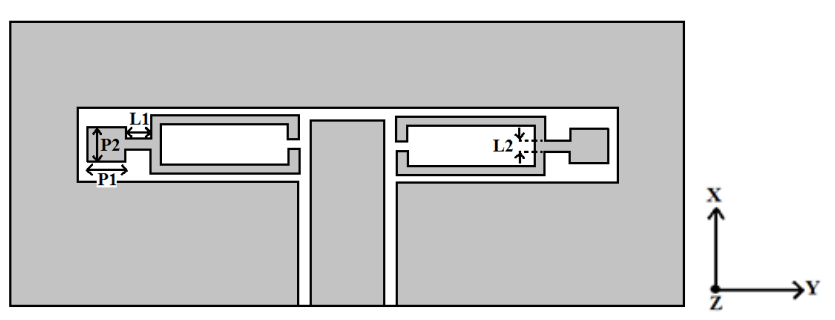

(c)

Fig. 1. Top view of slot patch antenna (partial substrate is shown): (a) Antenna 1 (single band); (b) Antenna 2 (dual band); (c) Antenna 3 (triple band).

metallic radiators at the two sides of the feedline inside the slot antenna. Its dimensions are $\mathrm{R} 1=2.4 \mathrm{~mm}, \mathrm{R} 2=6 \mathrm{~mm}$, $\mathrm{R} 3=0.4 \mathrm{~mm}, \mathrm{R} 4=1.6 \mathrm{~mm}$. In antenna 3 , two rectangular radiating patches are connected with the two split ring radiators with a metallic strip of dimensions $\mathrm{L} 1=1 \mathrm{~mm}$, $\mathrm{L} 2=0.4 \mathrm{~mm}$. The rectangular patches have dimensions $\mathrm{P} 1=1.6 \mathrm{~mm}, \mathrm{P} 2=1.4 \mathrm{~mm}$.

\subsection{Triple Band AMC Design}

Figure 2 exhibits the AMC surface along with its unit cell structure and simulation set-up. The surface consists of a $4 \times 4$ array of grounded metallic structures on FR4 substrate of dimensions $60 \mathrm{~mm} \times 60 \mathrm{~mm} \times 1.6 \mathrm{~mm}$. Figure 2(c) shows the arrangement of RIS unit cell for simulation. The grounded unit cell is placed in a radiation box. Two opposite faces of the box are made perfect electric conductor (PEC). The remaining two opposite faces are assigned the property of perfect magnetic conductor (PMC). These boundary conditions are used for imaging the unit cell to infinite extent in both $\mathrm{x}$ and $\mathrm{y}$ axes [19] thus giving an effect of periodic arrangement of the unit cell. Plane wave excitation is used where the electric field is parallel to $\mathrm{x}$-axis and the wave vector illuminates the surface of the RIS unit cell normally. The dimensions of the unit cell are given in Table 1. The AMC is placed at a dis-

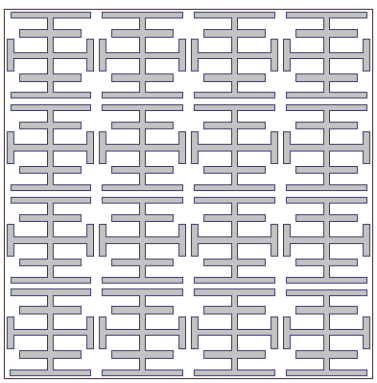

(a)

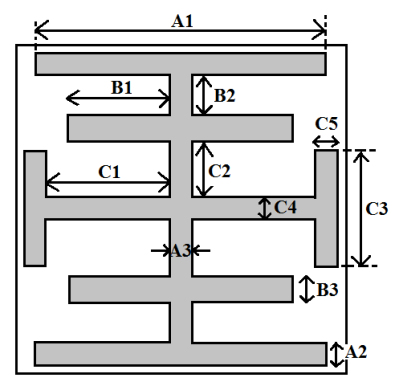

(b)
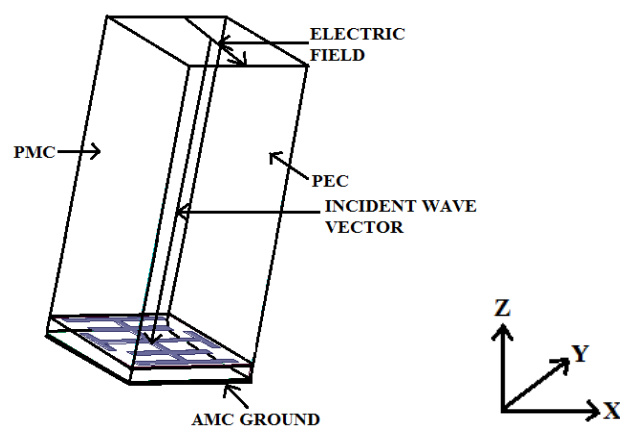

(c)

Fig. 2. AMC configuration: (a) AMC top surface; (b) AMC unit cell; (c) AMC unit cell simulation set up.

\begin{tabular}{|c|c|c|c|c|c|c|c|c|c|c|}
\hline A1 & A2 & A3 & B1 & B2 & B3 & C1 & C2 & C3 & C4 & C5 \\
\hline 12.9 & 1.0 & 1.0 & 3.87 & 1.8 & 1.2 & 5.5 & 2.5 & 5.2 & 1.0 & 1.0 \\
\hline
\end{tabular}

Tab. 1. Dimensions of AMC unit cell (in mm).

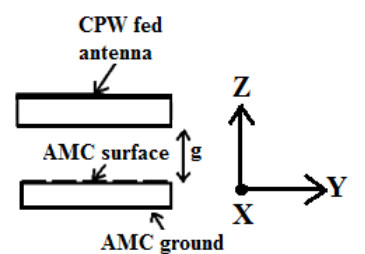

Fig. 3. Orientation of antenna (Antenna 3) with AMC (side view).

tance of $g=5.9 \mathrm{~mm}$ below the antenna as shown in Fig. 3 . This is the minimum distance found through simulation which gives good impedance matching.

\subsection{Analytical Modeling of Triple Band AMC}

At frequencies when the surface behaves as AMC (when reflection phase is null), a resonance occurs. Hence, the resonance phenomenon of the unit cell has to be investigated. In Fig. 4a, the metallic strip responsible for first resonance of the AMC is marked in blue color. The strip acts as a stepped impedance resonator (SIR) supporting a quasi-TEM mode of wave propagation. Figure $4 \mathrm{~b}$ illustrates the SIR separately. Referring to this figure, the resonance condition of SIR is [20], [21],

$$
\tan \left(\theta_{1}\right) \tan \left(\theta_{2}\right)=\frac{Z_{3}}{Z_{1}} .
$$




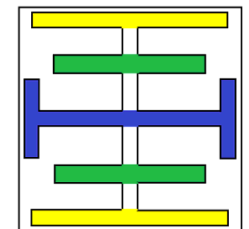

(a)

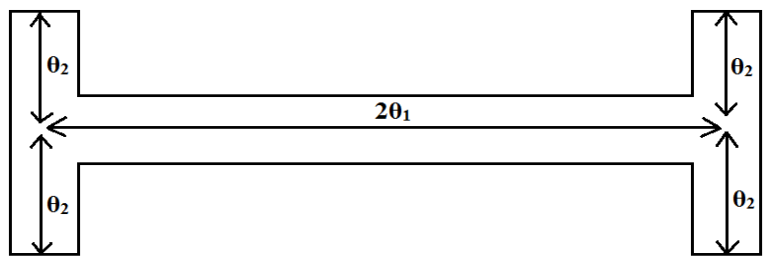

(b)

Fig. 4. (a) AMC unit cell identifying various regions responsible for its resonance; (b) Stepped Impedance Resonator illustrating its electrical lengths.

$Z_{1}$ is the characteristic impedance of the microstrip lines having electrical length $2 \theta_{1}$ and $Z_{3}$ is the characteristic impedance of the combination of two microstrip sections of electrical length $\theta_{2}$ at the end of the SIR which are in parallel connection (refer to Fig. 4b). If $Z_{2}$ is the characteristic impedance of each microstrip section of electrical length $\theta_{2}$, then $Z_{3}=Z_{2} / 2$. Hence, equation (1a) can be modified as

$$
\tan \left(\theta_{1}\right) \tan \left(\theta_{2}\right)=\frac{Z_{2}}{2 Z_{1}} \text {. }
$$

Characteristic impedance $Z$ of a microstrip line is given as [22]

$$
Z=\frac{60}{\sqrt{\varepsilon_{\text {eff }}}} \ln \left(\frac{8 d}{w}+\frac{w}{4 d}\right), \frac{w}{d} \leq 1 .
$$

Here, $w$ is the width of microstrip line and $d$ is the substrate thickness. The effective permittivity $\varepsilon_{\mathrm{eff}}$ can be determined as [22]

$$
\varepsilon_{\text {eff }}=\frac{\varepsilon_{\mathrm{r}}+1}{2}+\frac{\varepsilon_{\mathrm{r}}-1}{2}\left(1+12 \frac{d}{w}\right)^{-1 / 2} .
$$

The electrical lengths can be obtained as follows

$$
\begin{aligned}
& 2 \theta_{1}=\frac{2 \pi f}{c} \sqrt{\varepsilon_{\mathrm{eff}}} \cdot l_{1}, \\
& \theta_{2}=\frac{2 \pi f}{c} \sqrt{\varepsilon_{\mathrm{eff}}} \cdot l_{2} .
\end{aligned}
$$

Here, $f$ is the resonant frequency of the first mode of SIR, $c$ is the velocity of light, $l_{1}=2 \mathrm{C} 1+2 \mathrm{~mm}$ and $l_{2}=$ (C3) $/ 2+\Delta l$. The factor $\Delta l$ is introduced to account for the extra length contributed by the fringing electric field of open end microstrip line. $\Delta l$ is calculated from the following series of equations [23]

$$
\begin{gathered}
\Delta l=\frac{d Q_{1} Q_{3} Q_{5}}{Q_{4}}, \\
Q_{1}=0.434907 \frac{\varepsilon_{\mathrm{eff}}^{0.81}+0.26}{\varepsilon_{\mathrm{eff}}^{0.81}-0.189} \frac{\left(\frac{w}{d}\right)^{0.8544}+0.236}{\left(\frac{w}{d}\right)^{0.8544}+0.87},
\end{gathered}
$$

$$
\begin{gathered}
Q_{2}=1+\frac{\left(\frac{w}{d}\right)^{0.371}}{2.358 \varepsilon_{\mathrm{r}}+1}, \\
Q_{3}=1+\frac{0.5274}{\varepsilon_{\mathrm{eff}}^{0.9236}} \tan ^{-1}\left\{0.084\left(\frac{w}{d}\right)^{\frac{1.9413}{Q_{2}}}\right\}, \\
Q_{4}=1+0.0377\left\{6-5 e^{0.036\left(1-\varepsilon_{r}\right)}\right\} \tan ^{-1}\left\{0.067\left(\frac{w}{d}\right)^{1.456}\right\},(6) \\
Q_{5}=1-0.218 e^{-7.5 w / d} .
\end{gathered}
$$

On solving (1-6), the first resonant frequency of the AMC (given by $f_{1}$ ) can be obtained.

The metallic strips contributing to the next two resonant frequencies of the AMC are marked in yellow (for the second resonance) and green (for the third resonance) colors in Fig. 4a. Each of the metallic strip acts as a half wave resonating structure corresponding to their respective resonant frequencies. The length of the yellow strip is $l_{3}=$ $\mathrm{A} 1+2 \Delta l$. In this case, the metallic strip is open at both the ends. Hence, for each end, an extra length $\Delta l$ is taken to calculate the effective length of the metal strip. The length of the green strip is $l_{4}=2 \mathrm{~B} 1+2 \Delta l+1 \mathrm{~mm}$. Hence, the second and third resonant frequencies $f_{2}$ and $f_{3}$ respectively, are obtained as,

$$
\begin{aligned}
& f_{2}=\frac{c}{2 l_{3} \sqrt{\varepsilon_{\mathrm{eff}}}}, \\
& f_{3}=\frac{c}{2 l_{4} \sqrt{\varepsilon_{\mathrm{eff}}}} .
\end{aligned}
$$

\section{Results and Discussions}

\subsection{Triple Band Antenna Response}

Figure 5 presents the $\left|S_{11}\right|$ characteristic of the triple band antenna. The slot radiator has a resonant frequency at $3.60 \mathrm{GHz}$. As the metallic split ring radiators are introduced, another resonance is obtained at $5.86 \mathrm{GHz}$. On incorporating the square patches, the third resonance is obtained at $8.53 \mathrm{GHz}$.

\subsection{Numerical Validation of Analytical Modeling of AMC}

Using finite element method based numerical software ANSYS HFSS v. 15, full wave simulation result of the reflection phase characteristic of the triple band AMC is obtained and illustrated in Fig. 6. From the figure, it is observed that the resonant frequencies predicted by the analytical modeling of the AMC are almost similar to the result obtained from full wave simulation. A comparison of the simulated and analytical results is tabulated in Tab. 2 . 


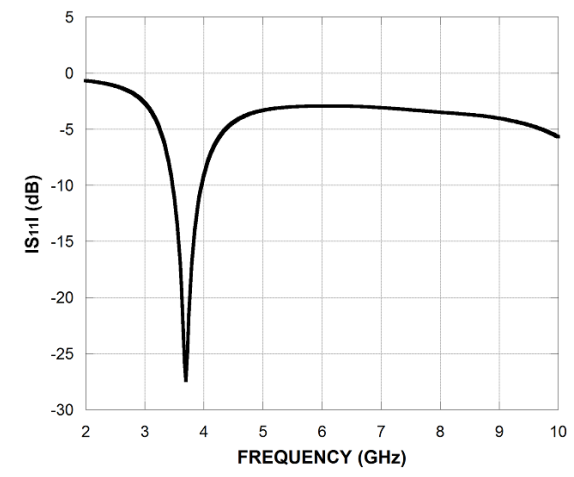

(a)

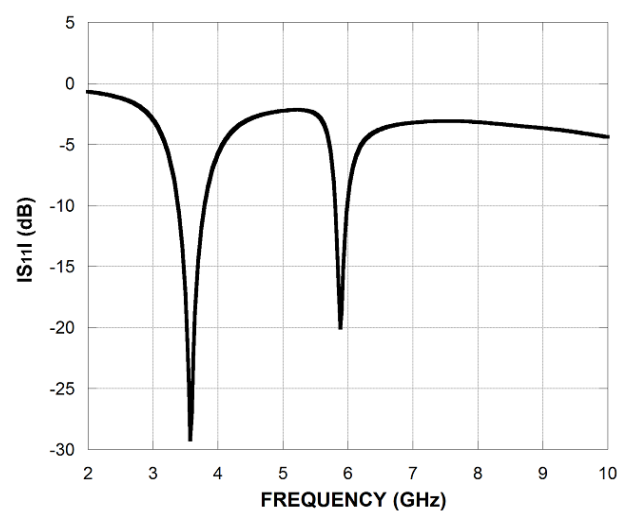

(b)

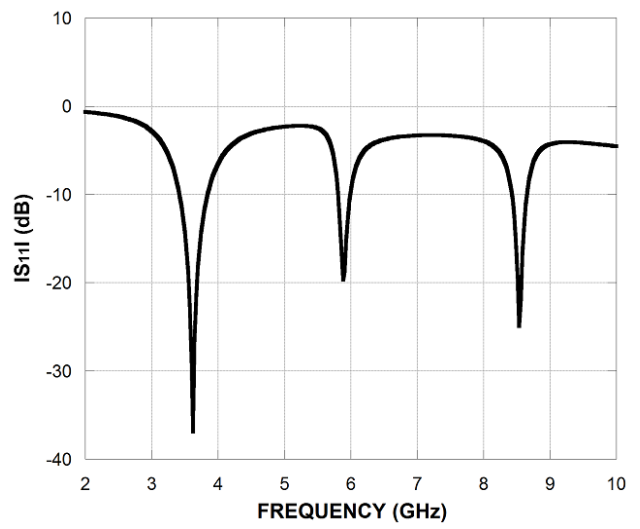

(c)

Fig. 5. Simulated $\left|S_{11}\right|$ response: (a) Antenna 1; (b) Antenna 2; (c) Antenna 3.

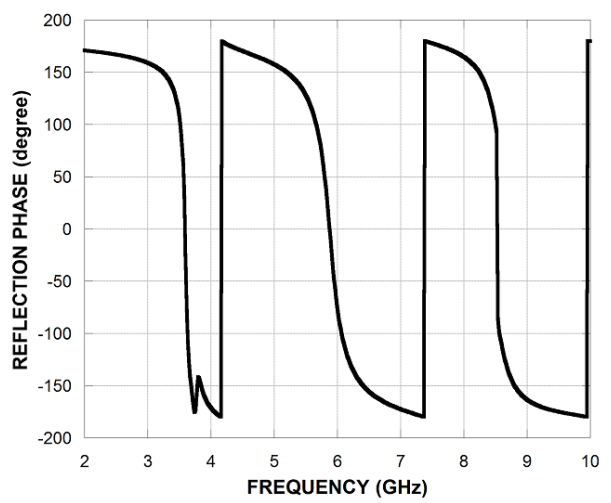

Fig. 6. Simulated Reflection Phase characteristic of AMC surface.

\begin{tabular}{|c|c|c|c|}
\hline & $\begin{array}{c}\text { First } \\
\text { resonance }\end{array}$ & $\begin{array}{c}\text { Second } \\
\text { resonance }\end{array}$ & $\begin{array}{c}\text { Third } \\
\text { resonance }\end{array}$ \\
\hline Analytical & $3.85 \mathrm{GHz}$ & $6.13 \mathrm{GHz}$ & $8.60 \mathrm{GHz}$ \\
\hline Simulation & $3.60 \mathrm{GHz}$ & $5.89 \mathrm{GHz}$ & $8.53 \mathrm{GHz}$ \\
\hline
\end{tabular}

Tab. 2. Comparison of results obtained from analytical modeling and simulation.

The resonant frequencies where the AMC exhibits zero reflection phase almost coincide with the resonant frequencies of Antenna 3. Hence, the AMC can be conveniently used for gain enhancement of Antenna 3. As observed from Fig. 6, the bandwidth of the AMC, defined as the frequency range where the reflection phase varies between $\pm 90^{\circ}$ [13], is $3.40 \%, 5.42 \%$ and $1.29 \%$ at $3.60 \mathrm{GHz}, 5.89 \mathrm{GHz}$ and $8.53 \mathrm{GHz}$ respectively. It is to be noted that the narrow bandwidth is a characteristic of multiband AMC as seen in previous literature [14-18].

\subsection{Gain Enhancement of Triple Band Antenna with Triple Band AMC}

A comparison of gain and bandwidth (BW) of Antenna 3 with and without AMC is presented in Tab. 3. The results highlight that significant gain enhancement is achieved in all the three bands after using the AMC. The bandwidths of the antenna change very slightly after using the AMC which can be neglected. The reason of gain enhancement can be attributed to the inphase reflection property of AMC due to which back radiated waves of the antenna are reflected by the AMC without phase reversal. The reflected waves interfere constructively with the radiated waves of the antenna. This enhances the directivity of the antenna which, in turn, improves the gain.

A metal reflector is also capable of reflecting the electromagnetic waves. Since a metal surface reflects waves $180^{\circ}$ out of phase with the incident wave, for constructive interference with the radiated wave, it has to be placed at $\lambda / 4$ distance below the antenna ( $\lambda$ is the operating wavelength) which will increase the profile of the structure. Moreover, since the antenna is triple band, it will have three different values of quarter wavelength. Hence, using a common reflector to increase the gain at all the three frequencies simultaneously is not possible. In order to validate this statement, a simulation has been performed by placing a metal reflector below Antenna 3 at the same distance as the AMC and it is seen that though the $\left|S_{11}\right|$ response of the antenna remains almost similar, the gain deteriorates at all the three resonant frequencies.

\begin{tabular}{|c|c|c|c|c|c|c|c|c|c|}
\hline & \multicolumn{3}{|c|}{ First resonance } & \multicolumn{2}{c|}{ Second resonance } & \multicolumn{3}{c|}{ Third resonance } \\
\cline { 2 - 9 } & $\begin{array}{c}\text { Freq. } \\
(\mathbf{G H z})\end{array}$ & $\begin{array}{c}\text { Gain } \\
(\mathbf{d B i})\end{array}$ & $\begin{array}{c}\text { BW } \\
(\mathbf{\%})\end{array}$ & $\begin{array}{c}\text { Freq. } \\
(\mathbf{G H z})\end{array}$ & $\begin{array}{c}\text { Gain } \\
(\mathbf{d B i})\end{array}$ & $\begin{array}{c}\text { BW } \\
(\mathbf{\%})\end{array}$ & $\begin{array}{c}\text { Freq. } \\
(\mathbf{G H z})\end{array}$ & $\begin{array}{c}\text { Gain } \\
(\mathbf{d B i})\end{array}$ & $\begin{array}{c}\text { BW } \\
(\mathbf{\%})\end{array}$ \\
\hline $\begin{array}{c}\text { With } \\
\text { AMC }\end{array}$ & 3.75 & 6.40 & 8.25 & 5.98 & 7.52 & 4.52 & 8.79 & 7.32 & 3.53 \\
\hline $\begin{array}{c}\text { Without } \\
\text { AMC }\end{array}$ & 3.60 & 1.45 & 9.72 & 5.86 & 3.64 & 3.41 & 8.53 & 3.19 & 2.68 \\
\hline
\end{tabular}

Tab. 3. Comparison of gain and bandwidth of Antenna 3 with and without AMC (simulated). 


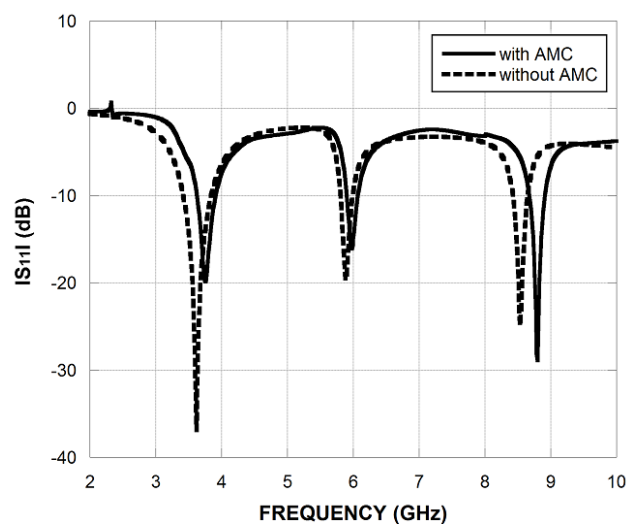

Fig. 7. Comparison of $\left|S_{11}\right|$ response of Antenna 3 with and without AMC

Figure 7 shows that the $\left|S_{11}\right|$ response of Antenna 3 remains almost unperturbed after using the AMC.

\section{Fabrication and Measurement Results}

Figure 8 shows the photograph of the fabricated triple band antenna and AMC. The $\left|\mathrm{S}_{11}\right|$ characteristic of the antenna with AMC is measured with Vector Network Analyzer of make Agilent PNA-L 5235A. The measured $\left|S_{11}\right|$ response shown in Fig. 9 reveals that the response is almost similar to the simulated response. The slight deviation from simulation result is due to some fabrication error. Gain of the structure is measured and presented in Fig. 10. The error in measured results is due to path loss, cable loss and interference due to reflection from multiple objects. The figure also compares the simulated gain of Antenna 3 with and without AMC and shows that in the entire operational bandwidth of the antenna, the gain is increased remarkably by the use of AMC.

Measured normalized radiation patterns of the structure in both E plane (XOZ plane) and $\mathrm{H}$ plane (YOZ plane) are given in Fig. 11 and found to be almost similar to the simulated results. To investigate the effect of the adopted AMC on the triple band antenna, simulated radiation patterns of Antenna 3 without AMC (reference) have also been included in the figure. The figure shows that the maximum radiation direction given by the major lobe re-

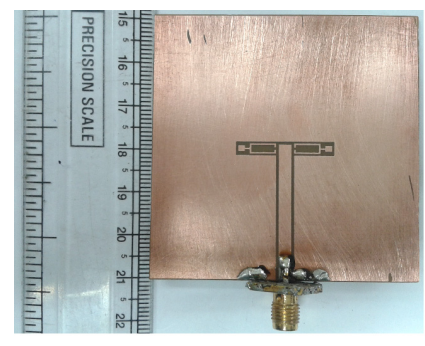

(a)

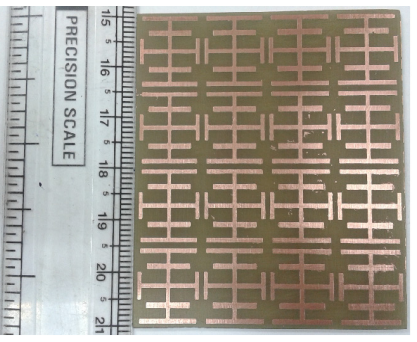

(b)
Fig. 8. Photograph of fabricated structure: (a) Triple band antenna; (b) Triple band Artificial Magnetic Conductor.

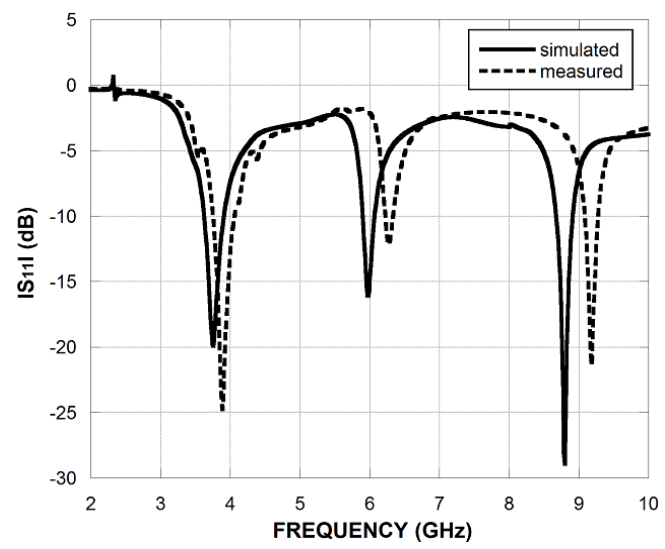

Fig. 9. Comparison of simulated and measured $\left|S_{11}\right|$ response of antenna with AMC.

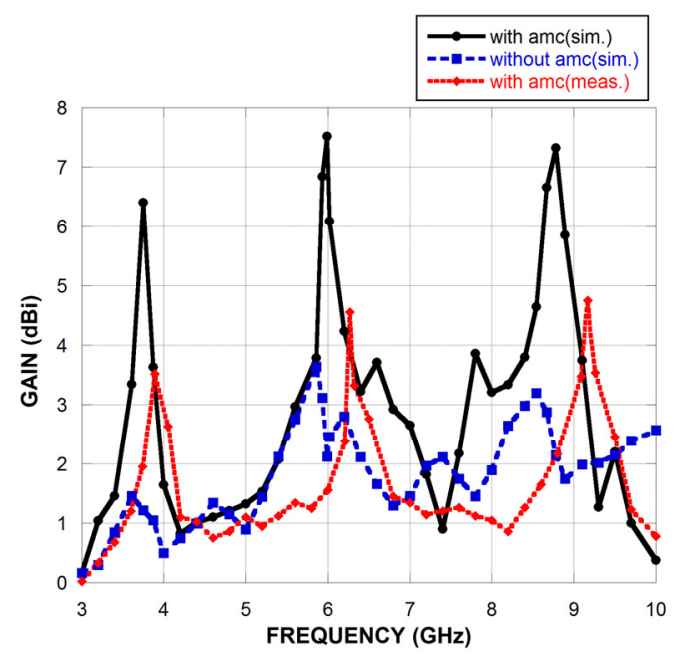

Fig. 10. Comparison of simulated and measured gain of antenna with AMC. Gain of antenna without AMC is also exhibited.

mains intact even after using the AMC. The backlobes are reduced due to the reflection of the back radiated waves by the AMC. A front-to-back ratio of nearly $14 \mathrm{~dB}$ or more is observed in the radiation patterns. The radiation patterns are stable in all the three frequencies with considerably low cross polarization level.

\section{Conclusion}

A triple band antenna has been designed with good impedance matching. The antenna has both slot and patch radiators. A triple band AMC has been designed and its analytical modeling is presented. The AMC is used in conjunction with the antenna. As a result, the gain of the antenna increases remarkably at all the three resonant frequencies without any noticeable change in $\left|S_{11}\right|$ response. The radiation patterns of the antenna with AMC exhibit very low cross polarization level as compared to the co polarization level at all the three frequencies. Moreover, due to the use of $\mathrm{AMC}$, the front-to back ratio of the antenna is improved at all the three resonant frequencies. 


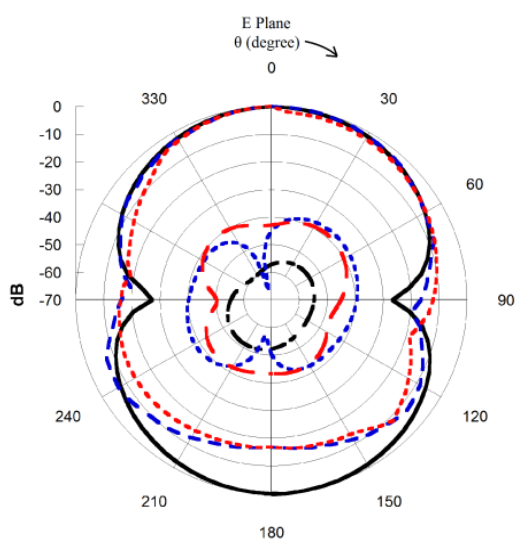

(a)

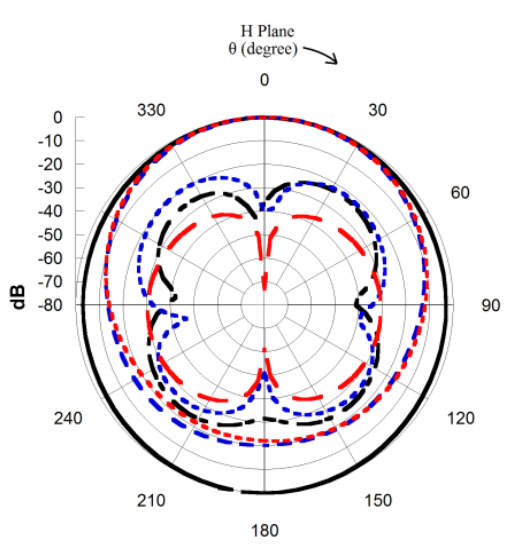

(d)

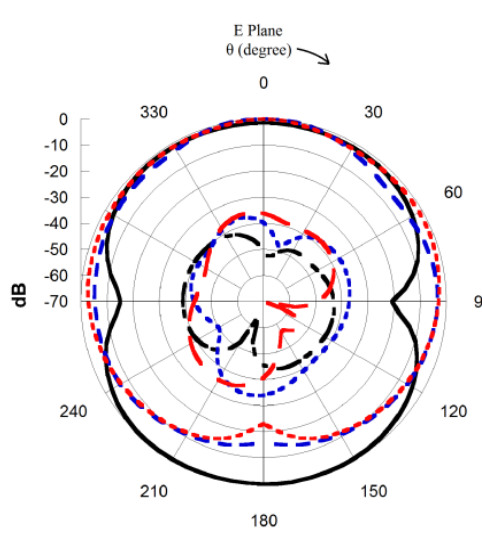

(b)

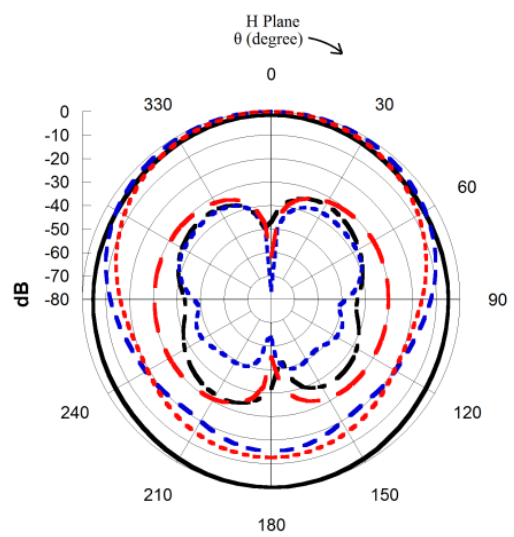

(e)

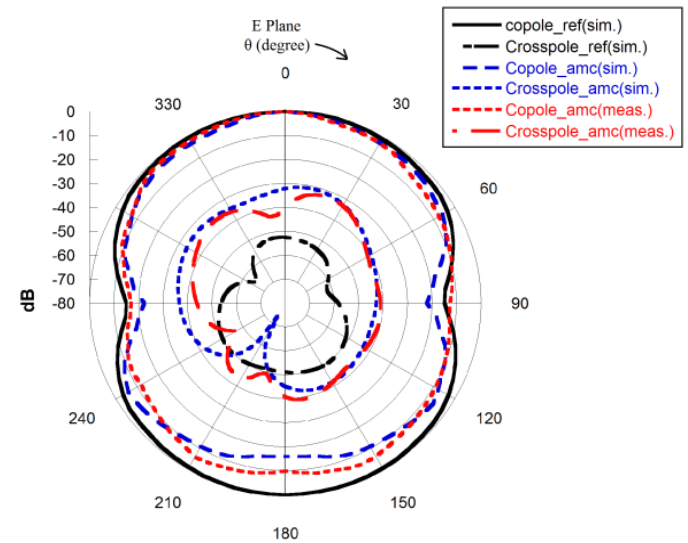

(c)

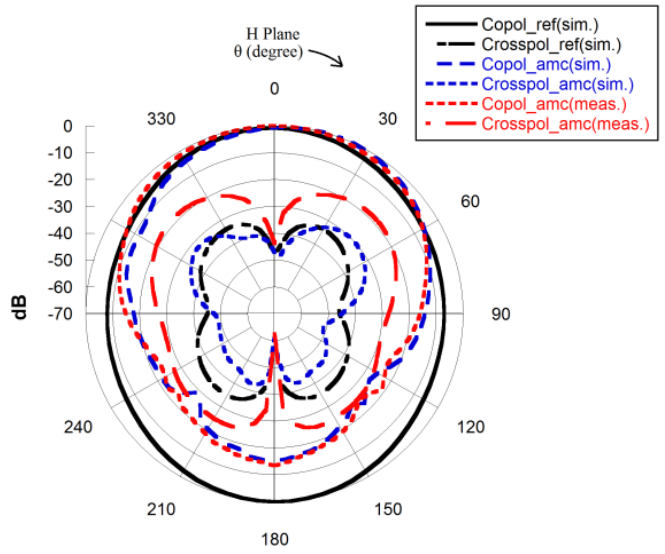

(f)

Fig. 11. Comparison of simulated and measured normalized radiation patterns of the triple band antenna with AMC: (a) E-Plane at $3.75 \mathrm{GHz}$; (b) E-Plane at $5.98 \mathrm{GHz}$; (c) E-Plane at $8.79 \mathrm{GHz}$; (d) H-Plane at $3.75 \mathrm{GHz}$; (e) H-Plane at $5.98 \mathrm{GHz}$; (f) H-Plane at $8.79 \mathrm{GHz}$.

\section{References}

[1] ANSARI, J.A., SINGH, P., DUBEY, S.K., et al. H-shaped stacked patch antenna for dual band operation. Progress in Electromagnetics Research B, 2008, vol. 5, p. 291-302. DOI: 10.2528/PIERB08031203

[2] FALADE, O.P., REHMAN, M.U., GAO, Y., et al. Single feed stacked patch circular polarized antenna for triple band GPS receivers. IEEE Transactions on Antennas and Propagation, 2012, vol. 60 , no. 10 , p. 4479-4484. DOI: 10.1109/TAP.2012.2207354

[3] JOSEPH, S., PAUL, B., MRIDULA, S., MOHANAN, P. A novel planar fractal antenna with CPW-feed for multiband applications. Radioengineering, 2013, vol. 22, no. 4, p. 1262-1266.

[4] SINGH, A.K., GANGWAR, R.K., KANAUJIA, B.K. Orthogonal slot-loaded coaxially stacked annular ring antenna with circular patch for multiband applications. Journal of Electromagnetic Waves and Applications, 2015, vol. 29, no. 12, p. 1630-1643. DOI: $10.1080 / 09205071.2015 .1054956$

[5] LI, F., REN, L.S., ZHAO, G., JIAO, Y.C. Compact triple band monopole antenna with $\mathrm{C}$-shaped and S-shaped meander strips for WLAN/WiMAX applications. Progress in Electromagnetics Research Letters, 2010, vol. 15, p. 117-126. DOI: 10.2528/PIERL10051704

[6] IDRIS, I.H., HAMID, M.R., JAMALUDDIN, M.H., et al. Single-, dual- and triple band frequency reconfigurable antenna. Radioengineering, 2014, vol. 23, no.3, p. 805-811.
[7] BAKARIYA, P.S., DWARI, S., SARKAR, M., MANDAL, M.K. Proximity-coupled multiband microstrip antenna for wireless applications. IEEE Antennas and Wireless Propagation Letters, 2015, vol. 14, p. 646-649. DOI: 10.1109/LAWP.2014.2376693

[8] FERESIDIS, A.P., VARDAXOGLOU, J.C. High gain planar antenna using optimised partially reflecting surfaces. IEE Proceedings-Microwaves, Antennas and Propagation, 2001, vol. 148, no. 6, p. 345-350. DOI: 10.1049/ip-map:20010828

[9] YANG, W., CHE, W., WANG, H. High gain design of a patch antenna using stub-loaded artificial magnetic conductor. IEEE Antennas and Wireless Propagation Letters, 2013, vol. 12, p. 1172-1175. DOI: 10.1109/LAWP.2013.2280576

[10] PARK, I.Y., KIM, D. High gain antenna using an intelligent artificial magnetic conductor ground plane. Journal of Electromagnetic Waves and Applications, 2013, vol. 27, no. 13, p. 1602-1610. DOI: 10.1080/09205071.2013.817957

[11] BOUZOUAD, M., CHAKER, S.M., BENSAFIELDDINE, D., LAAMARI, E.M. Gain enhancement with near-zero-index metamaterial superstrate. Applied Physics A, Materials Science \& Processing, 2015, vol. 121, no. 3, p. 1075-1080. DOI: 10.1007/s00339-015-9206-0

[12] KATIYAR, P., MAHADI, W.N.L.W. Impact analysis on distance variation between patch antenna and metamaterial. Microwave and Optical Technology Letters, 2015, vol. 57, no. 1, p. 178-183. DOI: 10.1002/mop.28809

[13] SIEVENPIPER, P., ZHANG, L., BROAS, R.F.J., et al. Highimpedance electromagnetic surfaces with a forbidden frequency 
band. IEEE Transactions on Microwave Theory and Techniques, 1999, vol. 47, no. 11, p. 2059-2074. DOI: 10.1109/22.798001

[14] SAAD, R., FORD, K.L. Miniaturised dual-band artificial magnetic conductor with reduced mutual coupling. Electronics Letters, 2012, vol. 48, no. 8, p. 425-426. DOI: 10.1049/el.2012.0709

[15] ABBASI, N.A., LANGLEY, R.J. Multiband-integrated antenna/artificial magnetic conductor. IET Microwaves, Antennas and Propagation, 2011, vol. 5, no. 6, p. 711-717. DOI: 10.1049/iet-map.2010.0200

[16] ABU, M., RAHIM, M.K.A. Single-band and dual-band artificial magnetic conductor ground planes for multi-band dipole antenna. Radioengineering, 2012, vol. 21, no. 4, p. 999-1006.

[17] ABU, M., RAHIM, M.K.A., AYOP, O., et al. Design of tripleband dipole-type antenna with dual-band artificial magnetic conductor structure. In Proceedings of the 5th European Conference on Antennas and Propagation. Rome (Italy), 2011, p. 1514-1517. ISBN: 978-1-4577-0250-1

[18] DEWAN, R., RAHIM, M.K.A., HAMID, M.R., et al. Analysis of triple band artificial magnetic conductor (AMC) band conditions to wideband antenna performance. In IEEE Asia-Pacific Conference on Applied Electromagnetics. Johor Bahru (Malaysia), 2014, p. 167-170. DOI: 10.1109/APACE.2014.7043770

[19] IHSAN, R.R., MUNIR, A. Utilization of artificial magnetic conductor for bandwidth enhancement of square patch antenna. In 7th International Conference on Telecommunication Systems, Services and Applications. Bali (Indonesia), 2012, p. 192-195. DOI: 10.1109/TSSA.2012.6366049

[20] MAKIMOTO, M., YAMASHITA, S. Bandpass filters using parallel coupled stripline stepped impedance resonators. IEEE Transactions on Microwave Theory and Techniques, 1980, vol. 28, no. 12 , p. 1413-1417. DOI: 10.1109/TMTT.1980.1130258

[21] SARRAZIN, J., LEPAGE, A.C., BEGAUD, X. Dual-band artificial magnetic conductor. Applied Physics A, Materials Science \& Processing, 2012, vol. 109, no. 4, p. 1075-1080. DOI: 10.1007/s00339-012-7409-1

[22] POZAR, D.M. Microwave Engineering. 4th ed. John Wiley \& Sons, Inc., 2012. ISBN: 978-0-470-63155-3

[23] KIRSCHNING, M., JANSEN, R.H., KOSTER, N.H.L. Accurate model for open end effect of microstrip lines. Electronics Letters, 1981, vol. 17, no. 3, p.123-125. DOI: 10.1049/el:19810088

\section{About the Authors ...}

Anumoy GHOSH was born in 1987. He received the
B. Tech. degree in Electronics and Communication Engineering from Kalyani Govt. Engineering College of West Bengal University of Technology, India, in 2010. He has done M.E. Degree from Bengal Engineering and Science University, Shibpur, India, in 2012. From 2012, he is pursuing $\mathrm{Ph} . \mathrm{D}$ in the Indian Institute of Engineering Science and Technology, Shibpur, India. Since 2014, he is associated with the Dept. of Electronics and Communication Engineering, National Institute of Technology, Mizoram, India and presently holds the post of an Assistant Professor. His current research interests include planar antennas, periodic structures and smart antennas.

Tapan MANDAL was born in1977. He received the B. Tech. degree in Electronics and Communication Engineering from Kalyani Govt. Engineering College of Kalyani University in 2001. He has done M.E. Degree from Bengal Engineering College (D.U.), Shibpur, India, in 2003. From 2004 to 2007, he worked as a Lecturer at the University Institute of Technology, Burdwan University. Since 2007, he is associated with the Dept. of Information Technology, Govt. College of Engineering and Textile Technology, Serampore, India and presently holds the post of an Asst. Professor. His current research interests include the planar printed antenna and electromagnetic band gap structures.

Santanu DAS was born in 1968. He received the B.E. degree in Electronics and Telecommunication Engineering from Bengal Engineering College of Calcutta University (India) in 1989 and M.E. degree in Microwave Engineering from Jadavpur University, Calcutta, in 1992. He obtained Ph.D. (Engineering) degree from Jadavpur University in 1998. He joined the Bengal Engineering and Science University, India in the year 1998, as a Lecturer in the Dept. of Electronics and Telecommunication Engineering and presently holds the post of a Professor. His current research interests include microstrip circuits, FSS, antenna elements and arrays. He is a life member of the Institution of Engineers, India. 